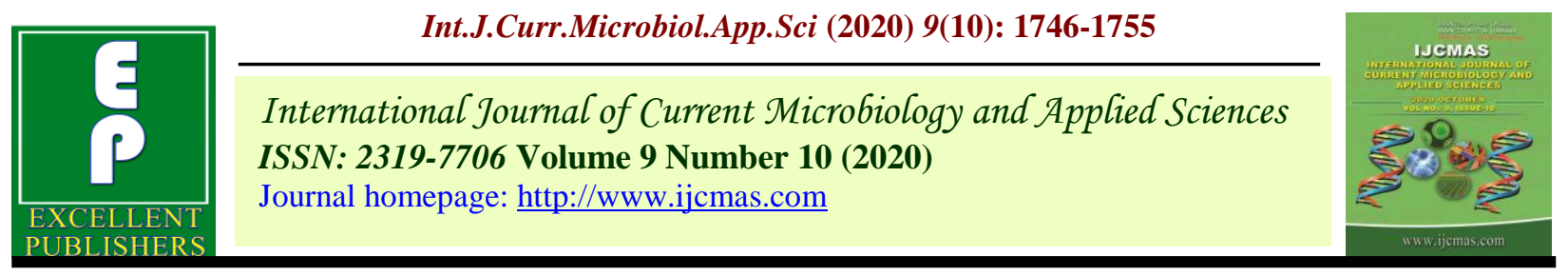

Original Research Article

https://doi.org/10.20546/ijcmas.2020.910.212

\title{
Composition of Essential Oils (EOs) and their Antifungal Activity against the $B$. cinerea
}

\author{
Shrikrishna Nishani ${ }^{{ }^{*}}$, Abhijit $\operatorname{Kar}^{1}$ and Robin Gogoi ${ }^{2}$ \\ ${ }^{1}$ Division of Postharvest Technology, ${ }^{2}$ Division of Plant Pathology, Indian Agricultural \\ Research Institute, India \\ *Corresponding author
}

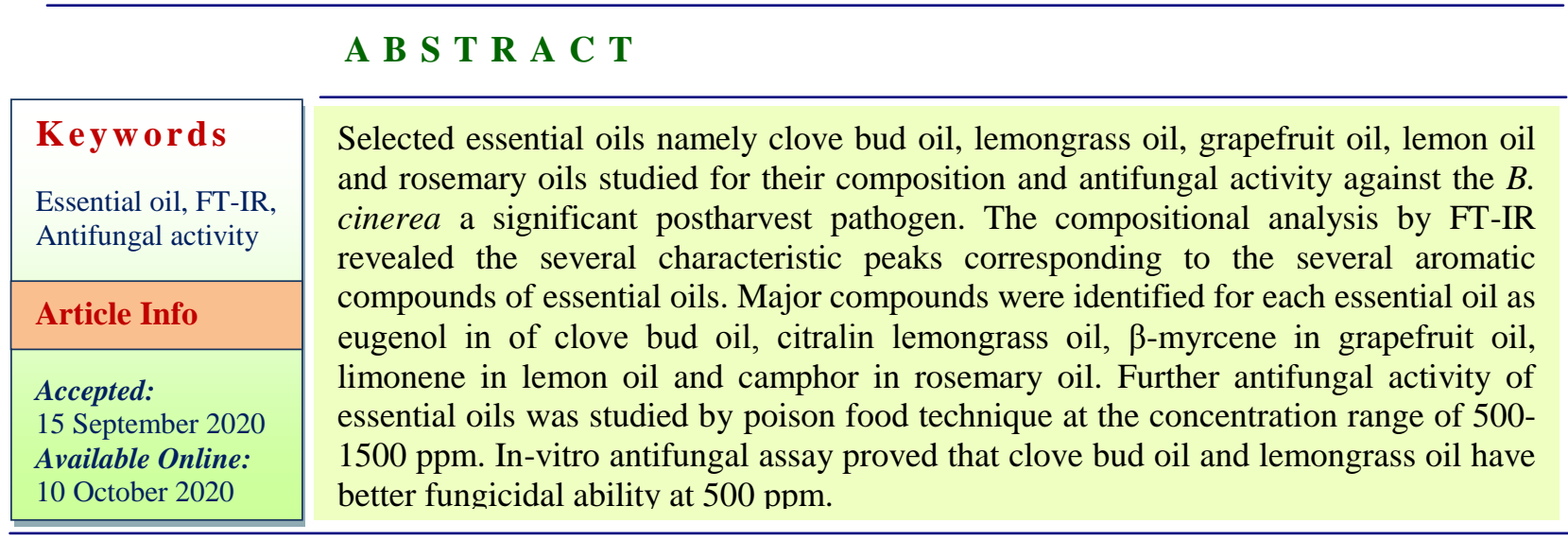

\section{Introduction}

Postharvest life of perishable goods undergoes heavy losses during the transport and storage due to the various biotic stresses. High moisture content, nutrients profile and $\mathrm{pH}$ makes them susceptible to the attack by microorganisms. Fruits having low $\mathrm{pH}$ are basically attacked by fungi and also contaminated by mycotoxins (Moss, 2002). Botrytis cinerea has been identified as remarkable post-harvest pathogens in fresh fruits and vegetables (Zhang et al., 2014). It poses big challenge during storage, shipment and marketing because of its different modes of infection and its ability to develop under different conditions prevailing.
The synthetic fungicides are basic means of managing these fungal incidences (Narayansamy, 2006). But they have recently come under scanner for posing a potential risk (Tripathi et al., 2008). Use of these chemicals has contaminated the commodities by fungicidal residues which have increased the public concern and also continuous use of fungicides has increased resistance in the pathogen populations (Tripathi and Dubey, 2004). The indiscriminate and excessive use of synthetic fungicides has been a prime cause for the development of resistant fungal pathogen populations, resulting in the use of even greater quantities of antifungal compounds in agriculture and the appearance of increased levels of toxic residues in food 
products (Da Cruz Cabral et al., 2013).Food safety is one of the striking concerns related to fresh fruit and vegetables (Antunes and Cavaco, 2010). The search for natural alternatives to synthetic fungicides is currently in the spotlight (Combrinck et al., 2011). To meet the consumer requirement for the natural and safe fresh foods, plant based extracts might be a good alternative to the use of synthetic fungicides (Gachangoet al., 2012).

Plant essential oils (EOs) and extracts have been used for thousands of years in food preservation, pharmaceuticals, alternative medicine and natural therapies (Prabuseenivasan et al., 2006). EOs, which is naturally synthesized in different plant organs as secondary metabolites, are characterized as oily fragrant liquids extracted from aromatic plant materials (El Asbahani et al., 2015).These plant essential oils could provide an alternative to synthetic chemicals to control post-harvest phytopathogenic fungi on fruit (Aminifard and Mohammadi, 2013). These essential oils contain several major and minor components which are responsible for their wide spectrum of activity. Generally, percentage of major compound influences the antifungal activity (Ipek et al., 2005). Some authors have reported their beneficial effect in controlling the postharvest diseases in fruits. Keeping this in view experiment was designed to evaluate the antifungal activity of some selected essential oils on significant postharvest fungi $B$. cinerea.

\section{Materials and Methods}

Clove bud oil, lemongrass oil, grapefruit oil, lemon oil and rosemary oil were purchased from the Allin exporters from the Uttar Pradesh, India. Fungal strain was obtained from the ITCC, Division of plant pathology, Indian Agricultural Research Institute, New delhi.

\section{FT-IR analysis of essential oils}

Samples were analyzed using a Fourier transform infrared spectrophotometer (Bruker ALPHA) equipped with a deuterated triglycine sulfate (DTGS) detector and ZnSe (Zinc Selenide) crystal single reflectance ATR. For each analysis, spectra scanning frequency ranged from 4,000 to $600 \mathrm{~cm}^{-1} .24$ scans were performed for each sample with resolution of $4 \mathrm{~cm}^{-1}$ at room temperature. Prior to each analysis, the background measurement was performed and ATR plate was cleaned using isopropyl alcohol. Data analysis was carried out using the OPUS 7.2 software (Bruker, U.K.).

\section{Antifungal assay of EOs}

Poisoned food technique (Grover and Moore, 1962) was used to evaluate the antifungal effect against molds. The 5 essential oils at various concentrations (500-1500 ppm) incorporated into the molten potato dextrose agar (PDA) and mixed well. Then, the PDA $(20 \mathrm{~mL} /$ plate $)$ is poured into Petri dishes.

The mycelial disc of5 $\mathrm{mm}$ diameter size was placed at the center of the plate. Plates were sealed in sterile condition with para film strip. Three replications for each treatment were tested. Plates are incubated at $35^{\circ} \mathrm{C}$, the diameters of fungal growth in control and sample plates were measured every alternate day and the antifungal activity is estimated by the following formula:

Antifungal activity $(\%)=\frac{D_{c}-D_{s}}{D_{c}} \times 100$

Where $D_{c}$ is the growth in control plate and $D_{s}$ is the growth in the plate containing tested essential oil. The effect was compared with carbendazim, commonly used systemic fungicide. 


\section{Results and Discussion}

\section{Fourier transform infrared spectroscope (FT-IR) of essential oils}

FTIR investigation of essential oil was done. The interpretation and identification spectrum was done by identifying intensity (High or low), shape (flat or sharp) and position (wavenumber) of source on the spectra (Hemalatha et al., 2016). FTIR spectra of clove bud oil showed several peaks corresponding to volatile compounds (Fig. 1) and characterized by peaks at $3522 \mathrm{~cm}^{-1}$ because of $\mathrm{O}-\mathrm{H}$ stretching, $2938 \mathrm{~cm}^{-1}$ due to $\mathrm{C}-\mathrm{H}$ stretching, at $1510 \mathrm{~cm}^{-1} 1605 \mathrm{~cm}^{-1}, 1451$ $\mathrm{cm}^{-1}$ because of stretching vibration of aromatic compound $\mathrm{C}=\mathrm{C}, 1265 \mathrm{~cm}^{-1} \mathrm{C}-\mathrm{O}$ stretching vibration in phenolic hydroxyl and $1231 \mathrm{~cm}^{-1}$ is due to $\mathrm{C}-\mathrm{O}$ bending were observed (Mohammed and Bayati 2009, Hasheminejad et al., 2019). Peaks at 1638 $\mathrm{cm}^{-1}$ indicates $\mathrm{C}-\mathrm{H}$ stretching vibration of benzene (Gao et al., 2017). Peaks from 1100$1210 \mathrm{~cm}^{-1}$ range indicates asymmetric stretch of C-O-C linkage of ether function group (Stuart 2004; Rodriguez et al., 2018).

FT-IR spectra of lemongrass is illustrated in the Fig. 2 in which peaks observed at 2980 $\mathrm{cm}^{-1}$ are of $\mathrm{C}-\mathrm{H}$ stretching of alkanes (Munhuweyi et al., 2017), sharp peaks at 2929 and $2856 \mathrm{~cm}^{-1}$ symmetric and asymmetric stretching of $\mathrm{CH}_{2}$ were observed. At $1274 \mathrm{~cm}^{-1}$ bending of $\mathrm{CH}_{3}$ group was found. Broad range from 1173 to $1016 \mathrm{~cm}^{-1}$, stretching of $\mathrm{C}-\mathrm{O}$ and vibrations of the $\mathrm{CH}$ were reported. The intense band observed at $1721 \mathrm{~cm}^{-1}$ corresponds to citral a common acyclic monoterpene is due to vibration of $\mathrm{C}=\mathrm{C}$ (cis and transisomers of citral), confirming the presence of conjugated double bonds ( $\mathrm{C}=\mathrm{C}-\mathrm{CHO}$ ) (Jamuna et al., 2017). The peak at $1633 \mathrm{~cm}^{-1}$ indicated the stretching of $\mathrm{C}=\mathrm{O}$ of aldehyde group (Natarajan et al., 2015). Peaks at $1445 \mathrm{~cm}^{-1}$ methylene $\mathrm{CH}$ bend, at $1366 \mathrm{~cm}^{-1}$ methyl $\mathrm{C}$-H symmetrical bend was observed (Vazquez-Briones et al., 2015). The peaks indicated the presence of cycloalkanes at $2500-3000 \mathrm{~cm}^{-1}$, terpinoids, flavonoids, carbonyl compounds and ketones at $1500-2000 \mathrm{~cm}^{-1}$ and methyl group, sulfonic acid and ester at 400-1500 $\mathrm{cm}^{-1}$ (Wany et al., 2014).

Rosemary oil spectrum was depicted in the Fig. 3 and found that peak observed at $3481.76 \mathrm{~cm}^{-1}$ are associated with $\mathrm{C}=\mathrm{C}$ stretch of different alkenes, at $2937.68 \mathrm{~cm}^{-1}$ and 2880 $\mathrm{cm}^{-1}$ strongest peaks are due to stretching of methyl groups, $1732.79 \mathrm{~cm}^{-1}$ which corresponding to stretching vibration of carbonyl group $\mathrm{C}=\mathrm{O}$ associated with camphor are observed (Fernade et al., 2013). Peak at $1371.52 \mathrm{~cm}^{-1}$ indicates $\mathrm{C}-\mathrm{O}$ bonding, at 1223 $\mathrm{cm}^{-1}$ asymmetric stretching of C-O-C and at $979 \mathrm{~cm}^{-1}$ wagging are associated with ether function from the epoxy ring of 1,8 cineole (Fernandes et al., 2013). Observed peaks at $881.80 \mathrm{~cm}^{-1}$ and $845.99 \mathrm{~cm}^{-1}$ are due to $\mathrm{C}-\mathrm{H}$ deformation (Rivera et al., 2016).

FT-IR spectrum of grape fruit oil (Fig. 4) showed peaks at $1580 \mathrm{~cm}^{-1}$ indicating that a monoterpene with nonaromatic conjugated $\mathrm{C}=\mathrm{C}$ double bond such as $\beta$ - myrcene. At $1732 \mathrm{~cm}^{-1}$ indicates $\mathrm{C}-\mathrm{O}$ mode of carboxyl group resonance with non-aromatic chain indicates the presence of different oxygen terpene such as citral. Peaks at 1271-1173 $\mathrm{cm}^{-1}$ antisymmetric and symmetric $\mathrm{C}-\mathrm{O}-\mathrm{C}$ stretching modes, indicates presence of esters such as linalyl acetate, observed peak at 2983 $\mathrm{cm}^{-1}$ corresponds to stretching mode of asymmetric $\mathrm{CH}_{3}$ groups, at $1118 \mathrm{~cm}^{-1}$ shows presence of least one constituent with aromatic ring and methoxy substitute. Peaks at $1446.91 \mathrm{~cm}^{-1}$ and $1391 \mathrm{~cm}^{-1}$ shows the asymmetric and symmetric bending of $\mathrm{CH}_{3}$ groups respectively, at $1366 \mathrm{~cm}^{-1}$ bending of $\mathrm{CH}_{2}$ groups of $\beta$ - myrcene were identified, at 1118-1014 $\mathrm{cm}^{-1}$ vibration of $\mathrm{C}-\mathrm{C}$ and $\mathrm{OH}$ 
groups, at $887 \mathrm{~cm}^{-1}$ out of plane bending of vinylidene group, was observed which is indicator of presence of limonene (Schulz et al., 2002; Manaila et al., 2016).

FT-IR analysis of lemon oil (Fig. 5) showed peaks at $2918.06 \mathrm{~cm}^{-1}$ stretching vibration of volatile terpenoids, at $1736.74 \mathrm{~cm}^{-1} \mathrm{C}=0$ stretching vibration of aldehyde and ester carbonyl group (key aroma compounds octanol, citral), peaks at $1681.12-1643.81 \mathrm{~cm}^{-}$
${ }^{1}$ showsvibration of $\mathrm{C}=\mathrm{C}$ occurring in the limonene molecules (Schulz et al., 2002; Elzey et al., 2016). Peaks at $1443.02 \mathrm{~cm}^{-1}$ and $1375.07 \mathrm{~cm}^{-1}$ indicates the deformation modes of $\mathrm{CH}_{3}$. At $1236.43 \mathrm{~cm}^{-1}, 1152.74-1019.24$ $\mathrm{cm}^{-1}$ vibrational of $\mathrm{C}-\mathrm{O}-\mathrm{C}$ mode shows the presence of linalyl acetate (Fidalgo et al., 2016). At $885.37 \mathrm{~cm}^{-1}$ cyclohexane vibration of $\alpha$-Pinene, $792 \mathrm{~cm}^{-1}$ tri substituted double bond out of plane bending was observed from the spectrum.

Fig.1 FTIR spectrum of clove bud oil

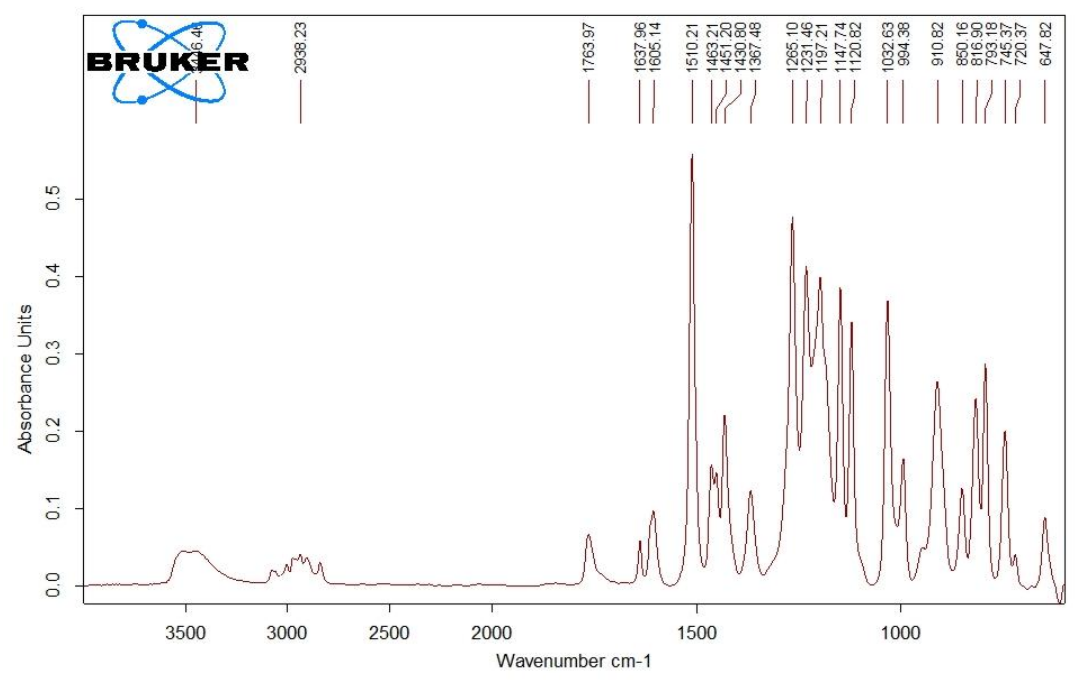

Fig.2 FT-IR spectrum of lemon grass oil

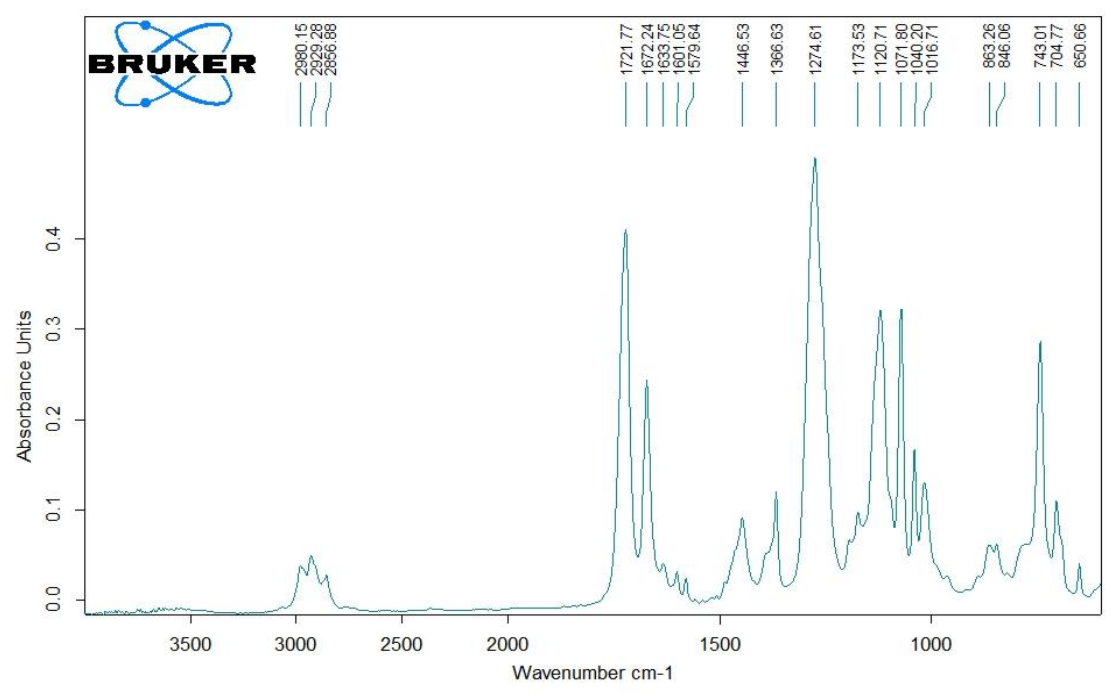


Int.J.Curr.Microbiol.App.Sci (2020) 9(10): 1746-1755

Fig.3 FT-IR spectrum of rosemary oil

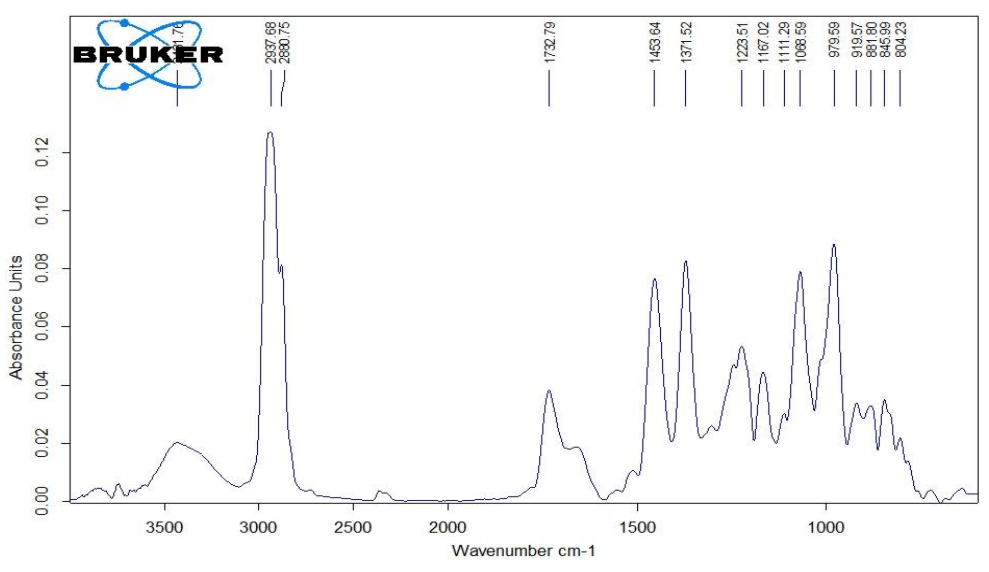

Fig.4 FT-IR spectrum of grape fruit oil

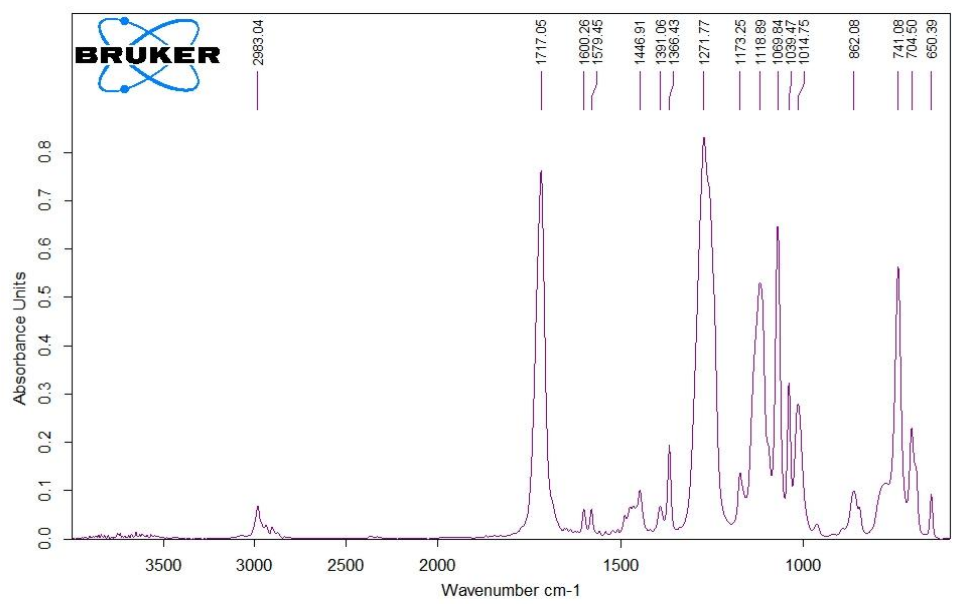

Fig.5 FT-IR spectrum of lemon oil

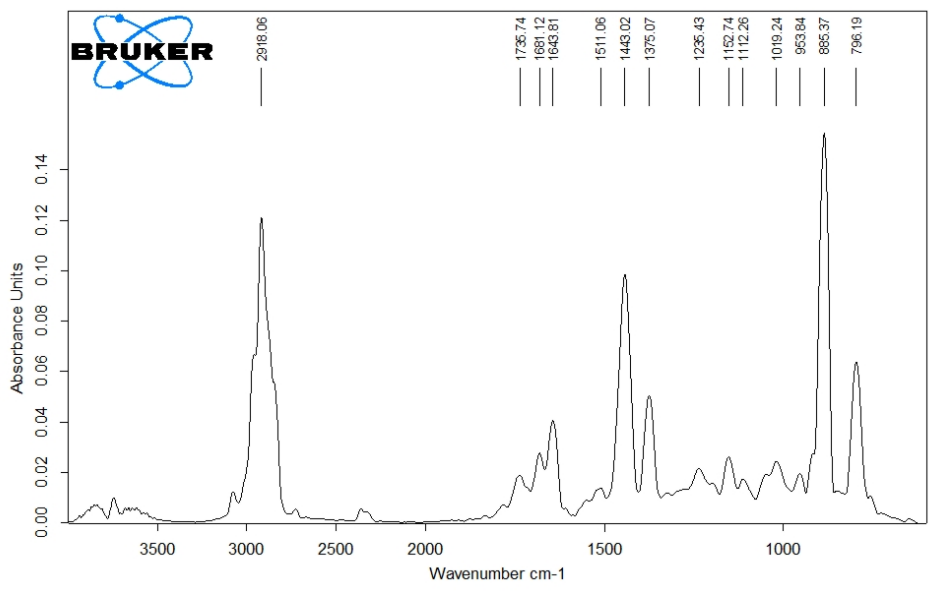


Fig.6 In-vitro antifungal activity of A) clove bud oil B) grape fruit oil C) lemongrass oil D) lemon oil and E) rosemary oil
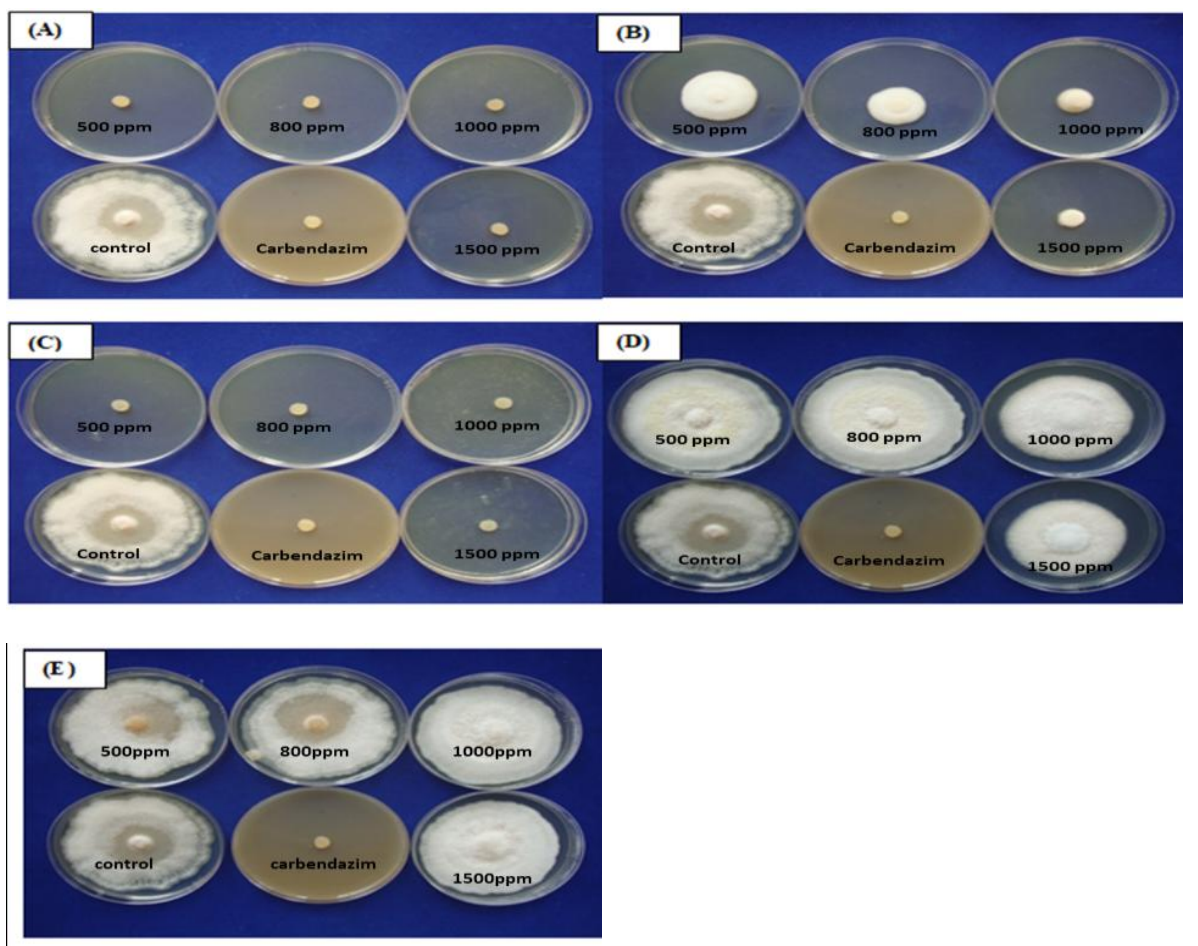

\section{Antifungal activity of the essential oils}

Antifungal activity of the essential was studied by poison food technique. Effects of the essential oils on the radial mycelial growth are presented in the figure 6. Essential oils inhibited the radial mycelial growth on concentration dependent manner. During seven days of incubation period the radial mycelial growth was found rapid in case of rosemary oil and lemon oil. Grape fruit oil restricts the growth of mycelia based on the concentration used. Clove bud oil and lemongrass oil proved to be fungicidal at concentration of $500 \mathrm{ppm}$. In case of the rosemary oil the end of incubation period mycelial growth was $8.8-9 \mathrm{~cm}$ and for lemon oil $6.9-9 \mathrm{~cm}$ at different concentrations. Grape fruit oil showed significant $(\mathrm{p}<0.05)$ effect in controlling the radial mycelial growth of $B$. cinerea. This difference in the inhibitory activity of the essential oils is due to the chemical structure of the individual components of EOs which in turn affect the particular mode of action and antifungal activity (Dorman and Deans, 2000). Antimicrobial property of the essential oils is also attributed to the phenolic nature of the essential oils (Bajpai et al., 2012). In general the essential oil which exhibit high antimicrobial property contain the high percentage of the phenolic compounds (Lambert et al., 2001; Burt, 2004).

Their mechanism of action appears to be predominantly on the fungal cell membrane, disrupting its structure causing leakage and cell death; blocking the membrane synthesis; inhibition of the spore germination, fungal proliferation and cellular respiration (Harris, 2002). The effective antifungal activity of the clove oil is attributed to its major components eugenol (Rana et al., 2011). Cox and Markham (2007) reported that eugenol may 
inactivate essential enzymes, react with the cell membrane or disturb the genetic material functionality thus resulting in death of microorganism. Antimicrobial activity of this oil can also be attributed to the presence of an aromatic nucleus and a phenolic $\mathrm{OH}$ group that are known to be reactive and can form hydrogen bonds with - $\mathrm{SH}$ groups in the active sites of target enzymes, resulting in the deactivation of enzymes in fungi (Vellutiet al., 2003).The efficient antifungal activity presented by lemongrass oil is significantly associated with the citral. In our study, the antifungal property of LGEO could be due to two major mono-terpene aldehydes (geranial and neral). The literatures suggest that the antifungal action of lemongrass oils could be due to the existence of high amounts of oxygenated monoterpenes (Boukhatemet al., 2014). Silva et al., (2008) and Kuritaet al., (1981) pointed out that the action of citral may be due to the ability of the compound to form a charge transfer complex with fungal cells electron donors, resulting in death of the fungus.

In conclusion the essential oils extracted from the natural plant sources have proved to meet the consumer preference for the safe and healthy fruits and vegetables. In the present study EOs displayed the potential to arrest the growth of the B.cinerea, a remarkable postharvest pathogen. Among the selected EOs the clove bud oil and lemongrass oil exhibited better fungicidal effect and grape fruit oil showed fungistatic effect on concentration dependent manner.

\section{References}

Moss, M. O. (2002). Mycotoxin review-1. Aspergillus and Penicillium. Mycologist, 16(3), 116-119.

Zhang, L., Kars, I., Essenstam, B., Liebrand, T. W., Wagemakers, L., Elberse, J and van Kan, J. A. (2014). Fungal endopolygalacturonases are recognized as microbe-associated molecular patterns by the arabidopsis receptor-like protein responsiveness to botrytis polygalacturonases1. Plant physiology, 164(1), 352-364.

Narayanasamy, P. (2006). Postharvest pathogen and disease management. John Wiley and Sons, Hoboken, NJ, USA.

Tripathi, P., Dubey, N. K and Shukla, A. K. (2008). Use of some essential oils as post-harvest botanical fungicides in the management of grey mould of grapes caused by Botrytis cinerea. World Journal of Microbiology and Biotechnology, 24(1), 39-46.

Tripathi, P and Dubey, N. K. (2004). Exploitation of natural products as an alternative strategy to control postharvest fungal rotting of fruit and vegetables. Postharvest Biology and Technology, 32(3), 235-245.

Da Cruz Cabral, L., Pinto, V. F and Patriarca, A. (2013). Application of plant derived compounds to control fungal spoilage and mycotoxin production in foods. International Journal of Food Microbiology, 166(1), 1-14.

Antunes, M. D. C and Cavaco, A. M. (2010). The use of essential oils for postharvest decay control. A review. Flavour and Fragrance Journal, 25(5), 351-366.

Combrinck, S., Regnier, T. andKamatou, G. P. (2011).In vitro activity of eighteen essential oils and some major components against common postharvest fungal pathogens of fruit. Industrial Crops and Products, 33(2), 344-349.

Gachango, E., Hanson, L. E., Rojas, A., Hao, J. J and Kirk, W. W. (2012). Fusarium sp. causing dry rot of seed potato tubers in Michigan and their sensitivity to fungicides. Plant Disease, 96(12), 1767-1774. 
Prabuseenivasan, S., Jayakumar, $M$ and Ignacimuthu, S. (2006). In vitro antibacterial activity of some plant essential oils. BMC complementary and alternative medicine, 6(1), 39.

El Asbahani, A., Miladi, K., Badri, W., Sala, M., Addi, E. A., Casabianca, $\mathrm{H}$ and Elaissari, A. (2015). Essential oils: from extraction to encapsulation. International journal of pharmaceutics, 483(1-2), 220-243.

Aminifard, M. H and Mohammadi, S. (2013). Efficacy of plant essential oils to control post-harvest decay of sweet cherry (Prunus avium L.) fruit. The Journal of Horticultural Science and Biotechnology, 88(1), 79-84.

Ipek, E., Zeytinoglu, H., Okay, S.,Tuylu, B. A., Kurkcuoglu, M and Baser, K. H. C. (2005). Genotoxicity and antigenotoxicity of Origanum oil and carvacrol evaluated by Ames Salmonella/microsomal test. Food Chemistry, 93(3), 551-556.

Grover, R. K and Moore, J. D. (1962). Toximetric studies of fungicides against brown rot organisms, Sclerotinia fructicola and S-Laxa. Phytopathology, 52(9), 876-880.

Dorman, H. D and Deans, S. G. (2000). Antimicrobial agents from plants: antibacterial activity of plant volatile oils. Journal of Applied Microbiology, 88(2), 308-316.

Bajpai, V. K., Baek, K. H and Kang, S. C. (2012). Control of Salmonella in foods by using essential oils: A review. Food Research International, 45(2), 722-734.

Lambert, R. J. W., Skandamis, P. N., Coote, P. J and Nychas, G. J. (2001). A study of the minimum inhibitory concentration and mode of action of oregano essential oil, thymol and carvacrol. Journal of Applied Microbiology, 91(3), 453-462.

Burt, S. (2004). Essential oils: their antibacterial properties and potential applications in foods- a review. International Journal of Food Microbiology, 94(3), 223-253.

Harris, R. (2002). Progress with superficial mycoses using essential oils. International Journal of Aromatherapy, 12(2), 83-91.

Rana, I. S., Rana, A. S and Rajak, R. C. (2011). Evaluation of antifungal activity in essential oil of the Syzygium aromaticum (L.) by extraction, purification and analysis of its main component eugenol. Brazilian Journal of Microbiology, 42(4), 1269-1277.

Cox, S. D and Markham, J. L. (2007). Susceptibility and intrinsic tolerance of Pseudomonas aeruginosa to selected plant volatile compounds. Journal of Applied Microbiology, 103(4), 930-936.

Velluti, A., Sanchis, V., Ramos, A. J., Egido, $\mathrm{J}$ and Marın, S. (2003). Inhibitory effect of cinnamon, clove, lemongrass, oregano and palmarose essential oils on growth and fumonisin B1 production by Fusarium proliferatum in maize grain. International Journal of Food Microbiology, 89(2-3), 145-154.

Boukhatem, M. N., Ferhat, M. A., Kameli, A., Saidi, F and Kebir, H. T. (2014). Lemon grass (Cymbopogon citratus) essential oil as a potent antiinflammatory and antifungal drugs. Libyan Journal of Medicine, 9(1).

Silva, C. D. B. D., Guterres, S. S., Weisheimer, V and Schapoval, E. E. (2008). Antifungal activity of the lemongrass oil and citral against Candida spp. Brazilian Journal of Infectious Diseases, 12(1), 63-66.

Kurita, N., Miyaji, M., Kurane, R and Takahara, Y. (1981). Antifungal activity of components of essential oils. Agricultural and Biological Chemistry, 45(4), 945-952.

Hemalatha, R., Nivetha, P., Mohanapriya, C., 
Sharmila, G., Muthukumaran, C andGopinath, M. (2016). Phytochemical composition, GC-MS analysis, in vitro antioxidant and antibacterial potential of clove flower bud (Eugenia caryophyllus) methanolic extract. Journal of Food Science and Technology, 53(2), 1189-1198.

Mohammed, M. J and Al-Bayati, F. A. (2009). Isolation and identification of antibacterial compounds from Thymus kotschyanus aerial parts and Dianthus caryophyllus flower buds. Phytomedicine, 16(6-7), 632-637.

Hasheminejad, N., Khodaiyan, F and Safari, M. (2019). Improving the antifungal activity of clove essential oil encapsulated by chitosan nanoparticles. Food chemistry, 275, 113-122.

Gao, H., Yang, H and Wang, C. (2017). Controllable preparation and mechanism of nano-silver mediated by the microemulsion system of the clove oil. Results in physics, 7, 3130-3136.

Stuart, B. H. (2004). Spectral analysis. Infrared spectroscopy: fundamentals and applications, 45-70.

Rodríguez, J. D. W., Peyron, S., Rigou, P and Chalier, P. (2018). Rapid quantification of clove (Syzygium aromaticum) and spearmint (Menthaspicata) essential oils encapsulated in a complex organic matrix using an ATR-FTIR spectroscopic method. PloS one, 13(11), e0207401.

Munhuweyi, K., Caleb, O. J., Lennox, C. L., van Reenen, A. J and Opara, U. L. (2017). In vitro and in vivo antifungal activity of chitosan-essential oils against pomegranate fruit pathogens. Postharvest Biology and Technology, 129, 9-22.

Jamuna, S., Sadullah, S., Ashokkumar, R., Shanmuganathan, G and Mozhi, S. S. (2017). Potential antioxidant and cytoprotective effects of essential oil extracted from Cymbopogon citratus on OxLDL and $\mathrm{H}_{2} \mathrm{O}_{2}$ LDL induced Human Peripheral Blood Mononuclear Cells (PBMC). Food Science and Human Wellness, 6(2), 60-69.

Natrajan, D., Srinivasan, S., Sundar, K and Ravindran, A. (2015). Formulation of essential oil-loaded chitosan-alginate nanocapsules. Journal of Food and Drug Analysis, 23(3), 560-568.

Wany, A., Kumar, A., Nallapeta, S., Jha, S., Nigam, V. K and Pandey, D. M. (2014). Extraction and characterization of essential oil components based on geraniol and citronellol from Java citronella (Cymbopogon winterianus Jowitt). Plant growth regulation, 73(2), 133-145.

del Carmen Vazquez-Briones, M., Hernández, L. R and Guerrero-Beltrán, J. Á. (2015). Physicochemical and antioxidant properties of Cymbopogon citratus essential oil. Journal of Food Research, 4(3), 36.

Fernandes, R. V. D. B., Borges, S. V., Botrel, D. A., Silva, E. K., Costa, J. M. G. D and Queiroz, F. (2013). Microencapsulation of rosemary essential oil: characterization of particles. Drying Technology, 31(11), 1245-1254.

González-Rivera, J., Duce, C., Falconieri, D., Ferrari, C., Ghezzi, L., Piras, A and Tine, M. R. (2016). Coaxial microwave assisted hydro-distillation of essential oils from five different herbs (lavender, rosemary, sage, fennel seeds and clove buds): chemical composition and thermal analysis. Innovative Food Science \& Emerging Technologies, 33, 308-318.

Schulz, H., Schrader, B., Quilitzsch, R and Steuer, B. (2002). Quantitative analysis of various citrus oils by ATR/FT-IR and NIR-FT Raman spectroscopy. Applied Spectroscopy, 56(1), 117-124. 
Elzey, B., Norman, V., Stephenson, J., Pollard, D and Fakayode, S. O. (2016). Purity analysis of adulterated essential oils by FT-IR spectroscopy and partialleast-squares regression. Spectroscopy, 31, 26-37.

Fidalgo, A., Ciriminna, R., Carnaroglio, D., Tamburino, A., Cravotto, G., Grillo, G and Pagliaro, M. (2016). Eco-friendly extraction of pectin and essential oils from orange and lemon peels. ACS
Sustainable Chemistry \& Engineering, 4(4), 2243-2251.

Manaila, E., Berechet, M. D., Stelescu, M. D., Craciun, G., Mihaiescu, D. E., Purcareanu, B and Radu, M. (2016). Comparison between chemical compositions of some essential oils obtained by hydrodistillation from citrus peels. Rev. Chim.(Bucharest), 67(1).

\section{How to cite this article:}

Shrikrishna Nishani, Abhijit Kar and Robin Gogoi. 2020. Composition of Essential Oils (EOs) and their Antifungal Activity against the B. cinerea. Int.J.Curr.Microbiol.App.Sci. 9(10): 17461755. doi: https://doi.org/10.20546/ijcmas.2020.910.212 